\title{
Myocardial abscess - case report of a survivor of a fatal disease
}

\author{
Narayanappa D. ${ }^{1}$, Rajani H.S. ${ }^{2}$, Sunil Kumar S. ${ }^{3}$, Anil Kumar M.G. ${ }^{4}$, Chandrashekhar C. ${ }^{5}$ \\ ${ }^{1}$ Dr. Doddaiah Narayanappa, Professor, ${ }^{2}$ Dr. Hassan Sreenivasamurthy Rajani, Assistant Professor, ${ }^{3}$ Dr. Sunil Kumar S, \\ Professor, ${ }^{4}$ Dr. Anil Kumar M.G., Professor, ${ }^{5}$ Dr. Chandrashekhar C., Associate Professor, all authors are affiliated with \\ Department of Pediatrics, JSS Medical College, JSS Academy of Higher Education and Research; Mysore, India.
}

Corresponding Author: Dr. Rajani H.S., Assistant Professor, Department of Pediatrics, JSS Hospital Mahatma Gandhi Road, Mysore. E-mail: rajanihs@jssuni.edu.in

\begin{abstract}
Myocardial abscess is a rare and usually a fatal complication which is often secondary to infective endocarditis but it is relatively a rare manifestation of staphylococcal septicemia especially in pediatric population. Here we are presenting a case of intramural myocardial abscess following right thigh abscessand septicemia caused by MRSA in an immunocompetent child with no structural heart disease. Incision and drainage of thigh abscess with aggressive appropriate antibiotic therapy saved the child despite the fatal myocardial abscess. Even in the absence of Infective endocarditis in staphylococcal septicemia, it is mandatory to look for myocardial abscess for early diagnosis and betteroutcome. A high index of clinical suspicion is required to make a prompt diagnosis.
\end{abstract}

Keywords: Myocardial abscess, Staphylococcal septicemia, MRSA

\section{Introduction}

Myocardial abscess, a suppurative complication, is usually located in the myocardium, valves, perivalvular structures, endocardium and cardiac conduction system. This rare but life-threatening complication is usually secondary to the direct spread of bacterial infection from infective endocarditis or rarely caused by the septicemia from a remote tissue. In earlier days, an early diagnosis of myocardial abscess was very difficult, and most cases of myocardial abscess were usually found at autopsy. A high index of clinical suspicion aids in prompt diagnosis. Earlydiagnosis, aggressive medical therapy and timely surgical intervention may save life in this fatal condition. Myocardial abscess can manifest in variety of clinical scenarios ranging from an asymptomatic state to catastrophic myocardial wall rupture. Here, we report a case of myocardial abscesses caused by MRSA septicemiain an immunocompetent child with no structural heart disease, without any evidences of infective endocarditiswho survived with aggressive medical management with serial echocardiography monitoring without surgical intervention.

\section{Case Report}

A 4-year-old male patient presented to emergency department with complaints of swelling of right thigh and difficulty in moving the right lower limbsince 4 days. There was no history of intramuscular injections or recent trauma.
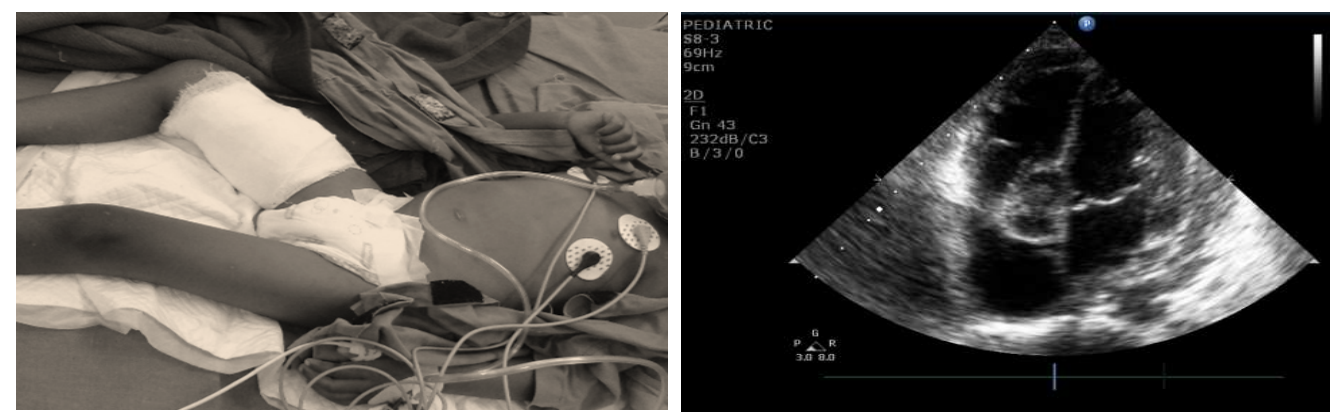

Figure-1: Child with right thigh abscess. Figure-2: First ECHO showing intramural abscess.

Manuscript received: $4^{\text {th }}$ February 2019

Reviewed: $14^{\text {th }}$ February 2019

Author Corrected: $18^{\text {th }}$ February 2019

Accepted for Publication: $21^{\text {st }}$ February 2019 

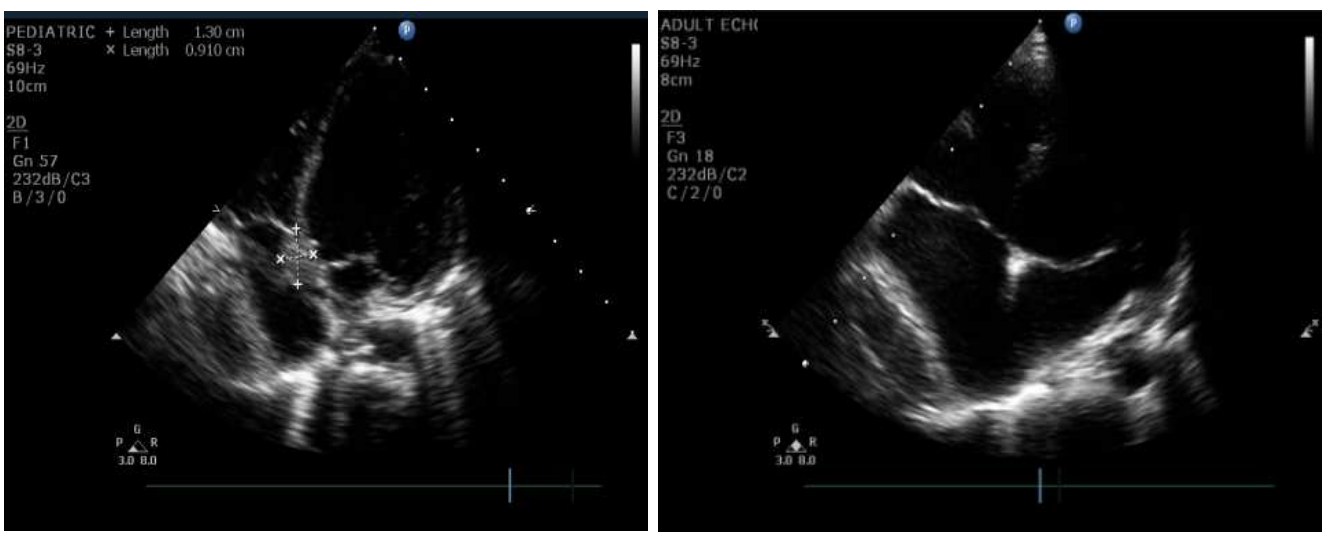

Figure-3: Second ECHO on day 13 showing reduction in size

Figure-4: ECHO done after 4 weeks of antibiotics showed complete resolution of abscess.

On examination patient was febrile, vitals were stable except for tachycardia. Child waspale with no icterus, clubbing, lymphadenopathy or cyanosis. Cardiac examination revealed normal heart sounds with no murmur or pericardial rub. Respiratory system, abdominal and neurological examination was unremarkable. Local examination revealed increased temperature, erythema, and induration over right thigh. Investigations were normal and values mentioned in Table 1. USG of right thigh suggested abscess. Incision and drainage wasdone, pus was sent for culture and sensitivity.

Patient was empirically treated with Ceftriaxone, Linezolid and Metronidazolealong with supportive care. In spite of debridement and antibiotics, child had persistent fever, tachypnea and tachycardia. Pus culture and sensitivity showed MRSA sensitive to Linezolid, Vancomycin, Teicoplanin, and Clindamycin. Hence Linezolid was continued, Clindamycin added and stopped Metronidazole. Patient developed shortness of breath, tachypnea, and hypotension 3 days later. Suspecting pericardial effusion, an emergency chest X-ray was done which showed cardiomegaly. 2D Echo revealed echogenic mass size $1.9 \times 1.6 \mathrm{~cm}$ situated at base of septal leaflet of tricuspid valve extending into Interventricular septum with mild pericardial effusion (fig.2). There wasno evidence of cardiac tamponade. Even though there wassuggestion of extension in to intraventricular septum, no conduction blocks were observed.

Table-1: Blood Investigations.

\begin{tabular}{|c|c|c|}
\hline Hemoglobin & $11.4 \mathrm{~g} / \mathrm{dl}$ & $11.5-15.5 \mathrm{gm} / \mathrm{dl}$ \\
\hline Total count & 4900 & $5.5-15 \times 10^{3} / \mathrm{mL}$ \\
\hline Platelets & $344 \times 10^{3} / \mathrm{mL}$ & $150-400 \times 10^{3} / \mathrm{mL}$ \\
\hline ESR & $8 \mathrm{~mm} / 1 \mathrm{hr}$ & $0-10 \mathrm{~mm} / 1 \mathrm{hr}$ \\
\hline Hematocrit & $39.2 \%$ & $35-45 \%$ \\
\hline SGOT & $51 \mathrm{U} / \mathrm{L}$ & $0-40 \mathrm{U} / 1$ \\
\hline SGPT & $48 \mathrm{U} / \mathrm{L}$ & $0-40 \mathrm{U} / 1$ \\
\hline ALP & $160 \mathrm{U} / \mathrm{L}$ & $37-147 \mathrm{U} / 1$ \\
\hline Blood sugar & $108 \mathrm{mg} / \mathrm{dL}$ & $70-150 \mathrm{mg} \%$ \\
\hline Total protein & $5.8 \mathrm{gm} / \mathrm{dl}$ & $6-8 \mathrm{gm} / \mathrm{dl}$ \\
\hline Total albumin & $3.5 \mathrm{gm} / \mathrm{dl}$ & $3.4-5.0 \mathrm{gm} / \mathrm{dl}$ \\
\hline Serum sodium & $136 \mathrm{mmol} / \mathrm{L}$ & $135-145 \mathrm{mmol} / \mathrm{L}$ \\
\hline Blood urea & $29 \mathrm{mg} / \mathrm{dl}$ & $20-40 \mathrm{mg} / \mathrm{dl}$ \\
\hline Serum creatinine & $0.5 \mathrm{mg} / \mathrm{dl}$ & $0.8-1.4 \mathrm{mg} / \mathrm{dl}$ \\
\hline
\end{tabular}

Monitoring was done with serial echo [1]. 2D echo done on tenth day showed decrease in the size of echogenic mass $1.3 \times 1 \mathrm{~cm}$ (fig.3). Child was given antibiotics for 4 weeks. Repeat 2D Echo after a month showed complete resolution of abscess (fig 4) and pericardial effusion with no evidence of constrictive physiology and child was discharged in stable condition and continued antibiotics for total 6 weeks. 


\section{Discussion}

Myocardial abscesses occurring as a complication of bacterial endocarditis or bacterial septicemia are relatively rare in the pediatric population. The presence of myocardial abscesses is commonly obscured by the symptoms of the associated generalized sepsis and is often only diagnosed by trans esophageal echocardiography during evaluation for infectious endocarditis (IE)[2].

Most commonly, abscesses result from direct extension from an infected cardiac valve to the surrounding perivalvular structures with subsequent formation of perivalvular abscesses. Free-wall myocardial abscesses may also result from septic coronary artery embolisms [3].

Myocardial abscesses that are seen with septicemia are usually multiple and small, and also associated with abscesses in multiple organs like kidneys, lungs, and brain [4]. Other conditions associated with myocardial abscesses are acute myocardial infarction, penetrating injuries, cardiac interventions, or infection with human immuno-deficiency virus which are less common in the pediatric population [4].

There are four previous reports of S. aureus bacterial pancarditis with myocardial abscess [5-8]. In children with Staphylococcus bacteremia, there is a $12 \%$ incidence ofInfective endocarditis and $90 \%$ of the reported cases are seen in children with underlying congenital heart disease $[5,8]$. The mortality rate has been as high as $40 \%$, as a result of cardiac tamponade [5].

In this case, high index of suspicion clinched the diagnosis of myocardial abscess in a structurally normal heart without any signs of cardiac tamponade. Throughout our patient's stay in hospital, serial echocardiography was crucial in diagnosis and monitoring.

A review of the literature done in 1999 by Shah et al found 16 patients with perivalvular abscesses associated with bacterial endocarditis during a 20 -year period. The patients' ages ranged from 8 to 21 years, and $40 \%$ of the patients had infection with $S$ aureus.

There have been a few subsequent pediatric case reports in the literature, but overall the incidence of this complication remains rare in comparison to adults, in whom up to $30 \%$ to $40 \%$ of patients with native valve IE have evidence of a myocardial abscess [8]. A reviewof infective endocarditis patients in India found that 7\% (14 of 192) had cardiac abscesses; however, only 2 of those 14 had myocardial abscesses that did not involve the valve or perivalvular areas [9].

\section{Conclusion}

Myocardial abscess is a life-threatening illness. A high index of clinical suspicion is required to make a prompt diagnosis. Final diagnosis may need multimodality imaging. An early diagnosis, aggressive medical therapy, multidisciplinary care and timely surgical intervention may save the patient's life in this otherwise fatal condition.

Funding: Nil, Conflict of interest: None initiated, Perission from IRB: Yes

Intramural myocardial abscess: Arare complication of MRSA infection in immune competent child.

\section{References}

1. Sunil Kumar S, Desai N, Narayanappa D, et al. A serial echocardiographic study of myocardial abscess in a patient surviving staphylococcal septicemia. Indian Heart J. 2014 Nov-Dec;66(6):743-4. doi: 10.1016/j.ihj. 2014. 12.010. Epub 2014 Dec 19.

2. Anguera I, Quaglio G, Ferrer B, et al. Sudden death in Staphylococcus aureus-associated infective endocarditis due to perforation of a free-wall myocardial abscess. Scand J Infect Dis. 2001;33 (8): $622-5$.

3. Chakrabarti J. Diagnostic evaluation of myocardial abscesses. A new look at an old problem. Int J Cardiol. 1995 Dec;52(3):189-96.

4. Iqbal J, Ahmed I, Baig W. Metastatic myocardial abscess on the posterior wall of the left ventricle: a case report. J Med Case Rep. 2008 Aug 5;2:258. doi: 10. 1186/1752-1947-2-258.

5. Yoon JK, Rahimi MB, Fiore A, Schowengerdt K, Jureidini SB. Bacterial pancarditis with myocardial abscess: successful surgical intervention in a 14-monthold boy. Tex Heart Inst J 2015; 42 (01) 55-57.

6. Gaur L, Madan S, Morell V, et al. Formation of ventricular aneurysm after endocarditis in a child with methicillin-resistant Staphylococcus aureus (MRSA) bacteremia. PediatrCardiol. 2011 Oct;32(7):1062-4. doi: 10.1007/s00246-011-0044-3. Epub 2011 Jul 26. 


\section{Case Report}

7. Schnoering H, Sachweh JS, Muehler EG, et al. Pancarditis in a five-year-old boy affecting tricuspid valve and ventricular septum. Eur J Cardiothorac Surg. 2008 Nov;34(5):1115-7. doi: 10.1016/j.ejcts.2008.07. 051. Epub 2008 Aug 27.

8. Valente AM, Jain R, Scheurer M, et al. Frequency of infective endocarditis among infants and children with Staphylococcus aureus bacteremia. Pediatrics. 2005 Jan;115(1): e15-9. Epub 2004 Dec 15. DOI:10.1542/ peds. 2004-1152
9. Choussat R, Thomas D, Isnard R, et al. Perivalvular abscesses associated with endocarditis; clinical features and prognostic factors of overall survival in a series of 233 cases. Perivalvular Abscesses French Multicentre Study. Eur Heart J. 1999 Feb;20(3):232-41.

10. Garg N, Kandpal B, Garg N, et al. Characteristics of infective endocarditis in a developing country-clinical profile and outcome in 192 Indian patients, 1992-2001. Int J Cardiol. 2005 Feb 15; 98 (2):253-60. DOI:10. 1016/j. ijcard. 2003.10.043

\section{How to cite this article?}

Narayanappa D, Rajani H.S, Sunil Kumar S, Anil Kumar M.G, Chandrashekhar C. Myocardial abscess - case report of a survivor of a fatal disease. Int J Pediatr Res. 2019;6(02):81-84. doi:10.17511/ijpr.2019.i02.06 